\title{
PCR FINGERPRINTING OF DIVERSE GENOMES FROM BACTERIAL STRAINS USING UNIVERSAL RICE PRIMER (URP)
}

\author{
Hee Wan Kang $1,2,3^{*}$ \\ ${ }^{1}$ Department of Horticultural life science, Hankyong National University, Ansung 17579, Korea \\ ${ }^{2}$ Institute of Genetic Engineering, Hankyong National University, Anseong 17579, Korea \\ ${ }^{3}$ JK BioTech.Co Ltd. Hankyong National University, Ansung 17579, Korea \\ *Corresponding author: kanghw2@hknu.ac.com
}

\begin{abstract}
Twenty primers of 20 mer referred to universal rice primer (URP) were developed from a repetitive sequence of rice genome. URP-PCR protocol employed stringent PCR with high annealing temperature throughout the thermo-cycling reaction, giving high reproducibility. Under the PCR condition, each single URP primer produced characteristic fingerprints from diverse genomes of bacterial species. The universal application of URP-PCR was demonstrated by applying it to 24 strains from Pectobacterium carotovoum subsp. carotovorum, 41 Agrobacterium vitis strains, 3 Xanthomonas spp. 5 Pseudomonas spp, Rhizobium sp. plant pathogenic bacteria, human and animal pathogenic bacterial strains including 6 Escherichia coli, 4 Salmonella spp., 7 Mycobacterium spp and 3 Blucella abortus strains. In addition, thermophilic bacteria were randomly isolated form high temperature compost and their URP-PCR polymorphisms were characterized with genetic relatedness. PCR approach using URP primers will be useful for studying DNA diversity of diverse prokaryotic genomes, especially at inter- and intra species levels.
\end{abstract}

Keywords: Diverse bacterial strains, PCR polymorphism, Universal Rice Primers

\section{INTRODUCTION}

The classic taxonomical methods of bacteria, relies on fatty acids, nutritional composition, and biochemical properties and so on (Garrity et al., 2002). However, it has been pointed out that microorganisms tend to lead to other consequences due to environmental effects, and that their shorter generation and higher rates of metamorphosis have been a limiting factor in the bacterial classification system. The sequence of $16 \mathrm{~S}$ rDNA was adopted as a new classification tool of the bacterial class (Chang et al., 1997), providing an opportunity for the revision of bacterial taxonomy to take place. In particular, inter transcribed spacer (ITS)-16S 
rDNA sequence region is widely used as a species-specific identification of bacterial species (Chang et al., 1997, Garrity et al., 2002 ). However, since these rDNA regions are highly preserved areas, there is a limit to find polymorphism at level of inter-species such as subspecies, pathovar and race strains within species. Various molecular typing methods such as extragenic palindromic (REP) sequence, 124-127 enterobacterial repetitive intergenic consensus (ERIC) sequence $154 \mathrm{bp}$ and $\mathrm{BOX}$ that are derived from repetitive sequences located in bacterial genomes have widely been used for discrimination of various bacterial strains at inter species level (De Brujin, 1992, Hulton et al., 1991) Recently, in silico genomic fingerprints were devised to be produced by virtual hybridization of 191 fully sequenced bacterial genomes using a set of 15,264 13mer probes specially designed to produce universal whole genome fingerprints(JaimesDiaz et al., 2011).

Multiple arbitrary amplicon profile (MAAP) that can universally be used in different organisms including pants, animals and microorganisms was developed for the use of single or multiple arbitrary primers (Caetano-Anolles, 1994; Caetano-Anolles and Gresshoff, 1997), and includes the techniques of RAPD (Williams et al., 1990),
AP-PCR (Welsh et al., 1990), and DNA amplification fingerprinting (DAF) (CaetanoAnolles et al., 1992). Because of its simplicity, the RAPD method has been used widely in studies of genetic diversity and in examining phylogenic and taxonomic relationship of bacterial strains (CaetanoAnolles and Gresshoff, 1997). However, in PCR techniques using arbitrary and RAPD primers, low reproducibility that causes variable PCR results depending on PCR condition has been recognized as a disadvantage factor (Caetano-Anolles et al., 1992).

A repeated DNA fragment (pKRD) of $1,187 \mathrm{bp}$ was isolated from a genomic library of weedy rice distributed in Korea. A homology search showed the pKRD sequence belonged to a putative transposable element, the CACTA-like $E n / S p m$ family Furthermore, pKRD was used as a molecular marker to detect genetic variation of rice germplasm (Kang and Kang, 2008). Twenty primers consisting of 20 oligonucleotides were randomly designed from the repetitive 
sequence, pKRD (Kang et al., 2002). Under species.

the high stringent PCR condition, twenty

primers of them can be applied in genomic

fingerprinting of a variety of organisms

including animals, other plants, and

microorganisms, as well as rice and named as

universal rice primer (URP). URP-PCR

technology has been applied for accessing

genetic diversity of various fungal and

bacterial species. Numerous papers have

demonstrated that URP-PCR profiles of

fungal species are very useful for identifying

microbial species at intra and inter species

levels (Aggarwal et al., 2010. Aggarwal et al,

2010; Hong et al., 2008; Jana et al., 2005;

Kang, 2012; Kang, 2001, Kang, 2002) and

further the specific PCR polymorphic bands

could be used for finding SCAR PCR primer

for diagnosis of bacterial species or strain

(Kang et al., 2003; Lim et al., 2007).

In this study, it was demonstrated that

URP primers can universally be applied to

PCR fingerprinting of diverse genomes from

plant, human, animal and industry related and O157:H7), 4 Salmonella spp., 7

bacterial strains at levels of intra and inter

Mycobacterium spp. and 3 Blucella abortus

\section{MATERIALS AND METHODS}

\section{Bacterial strains and genomic DNA}

extraction

Fourty one Agrobacterium vitis strains were isolated from different grapevein varieties by Hankyong National University. Twenty four strains of Pectobacterium carotovoum subsp. carotovorum, 3 Xanthomonas spp. 5 Pseudomonas spp, Rhizobium sp. of plant pathogenic bacteria were provided by Korea Agricultural Culture Collection (KACC). Themophilic bacterial strains containing Thermoactinomyces vulgaris that are randomly isolated form high temperature fermented compost were obtained from National Institute of Agricultural Sciences (NIAS), Rural Development Administration in Korea. DNA samples of human and animal related bacterial strains included 6 Escherichia coli strains (ATCC11105, 111a111b, M15, DH5, Mycobacterium spp. and 3 Blucella abortus 
strains were obtained from Medical School in Yeonsei University of Korea. Genomic DNA from gram negative and positive bacteria was extracted following the procedure described by Ausubel et al.(1987).

\section{PCR analysis}

URP with 20 mer were provided from JK BioTech, Co. Ltd., Ansung, Korea. PCR reactions were carried out in 50 ul reaction mixtures containing the DNA template (20 to $50 \mathrm{ng}$ of purified DNA), $10 \mathrm{mM}$ Tris- $\mathrm{HCl}, 50$ $\mathrm{mM} \mathrm{KCl}, 1.5 \mathrm{mM} \mathrm{MgCl} 2,0.01 \%$ gelatin, 200 $\mathrm{uM}$ of each dNTP, $200 \mathrm{ng}$ primer and 2.5 unit Taq DNA polymerase (Promega, USA). The reaction mixture was overlaid with a thin layer of sterile mineral oil to prevent evaporation. DNA amplification was performed in a programmable DNA thermal cycler (MJ Research, Inc., USA). The cycling parameters used were initial denaturation at $94^{\circ} \mathrm{C}$ for $4 \mathrm{~min}$, followed by 35 cycles each consisting of $1 \mathrm{~min}$ at $94^{\circ} \mathrm{C}, 1$ $\min$ at $55^{\circ} \mathrm{C}$, and $2 \mathrm{~min}$ at $72^{\circ} \mathrm{C}$. After the last cycle, the PCR tubes were incubated at $72^{\circ} \mathrm{C}$ profile of diverse bacteria including
PCR polymorphic bands based genetic relationship

PCR polymorphic bands were scored on their presence (value $=1$ ) or absence (value $=0$ ). The similarity coefficient was calculated by rearranging the scored bands of each rice variety. A dendrogram was constructed with the statistical program NTSYSpc (Rohlf, 2000) using the unweighted pair-group method with arithmetic mean (UPGMA).

\section{RESULTS AND DISCUSSIONS}

URP-PCR method was used to study the genetic diversity of $24 P$. carotovurum subsp carotovorum (Pcc) strains causing bacterial soft rot disease on different plant species and 9 additive plant pathogenic bacteria. Fig. 1 shows PCR fingerprinting 
Pectobacterium carotovorum subsp. tetraploid grapevine cultivars of Vitis vinifera carotovorum (Pcc), Xanthomonas (Kyohoand, Daebong), which are relatively axonopodis pv. citri, Pseudomonas spp., sensitive to A. vitis, were intensively planted Pseudomonas solanocearum, Rhizobium in farm fields (80\%) of Ansung and Cheonan leguminosarum, Pseudomonas $\quad \mathrm{pv}$ areas of Korea. Forty one strains of phaseoliala, Pseudomonas marginalis, Agrobacterium vitis, the causal agent of Xanthomonas campestris pv. campestris and crown-gall disease on grapevine (Fig. 2 A), Pseudomonas syrinage pv syringae using originating from different geographical URP 4. The PCR data revealed that the regions and 16 grapevine cultivars including majority of the bacterial strains have multiple 35 Kyoho cultivar of Korea, were banding patterns showing their PCR characterized by PCR fingerprinting using polymorphisms. Furthermore, the results URP 2 and URP 4(Fig. 2 B, C). A. vitis distinguished clearly difference among the strains originated from Kyoho cultivar of Pcc strains, showing their high genetic grapevine showed relatively simple genetic diversity. In the case of Pseudomonas species, diversity of the four PCR types, while the A. Pseudomonas pv phaseoliala and vitis strains originated from other grapevine Pseudomonas marginalis were divided as cultivars showed various genetic diversities closely related group showing analogous with 8 types. Comprehensively, UPGMA PCR pattern among the Pseudomonas species. analysis based genetic relationship using the Agrobacterium vitis, a soilborn bacterium, is URP-PCR polymorphic bands showed $41 A$. a causal agent of crown gall on grapevines. vitis strains are genetically clustered into Crown gall disease of grapevine has rapidly large seven groups and 17 subgroups in the become problematic in Korea because groups (Data not shown). 


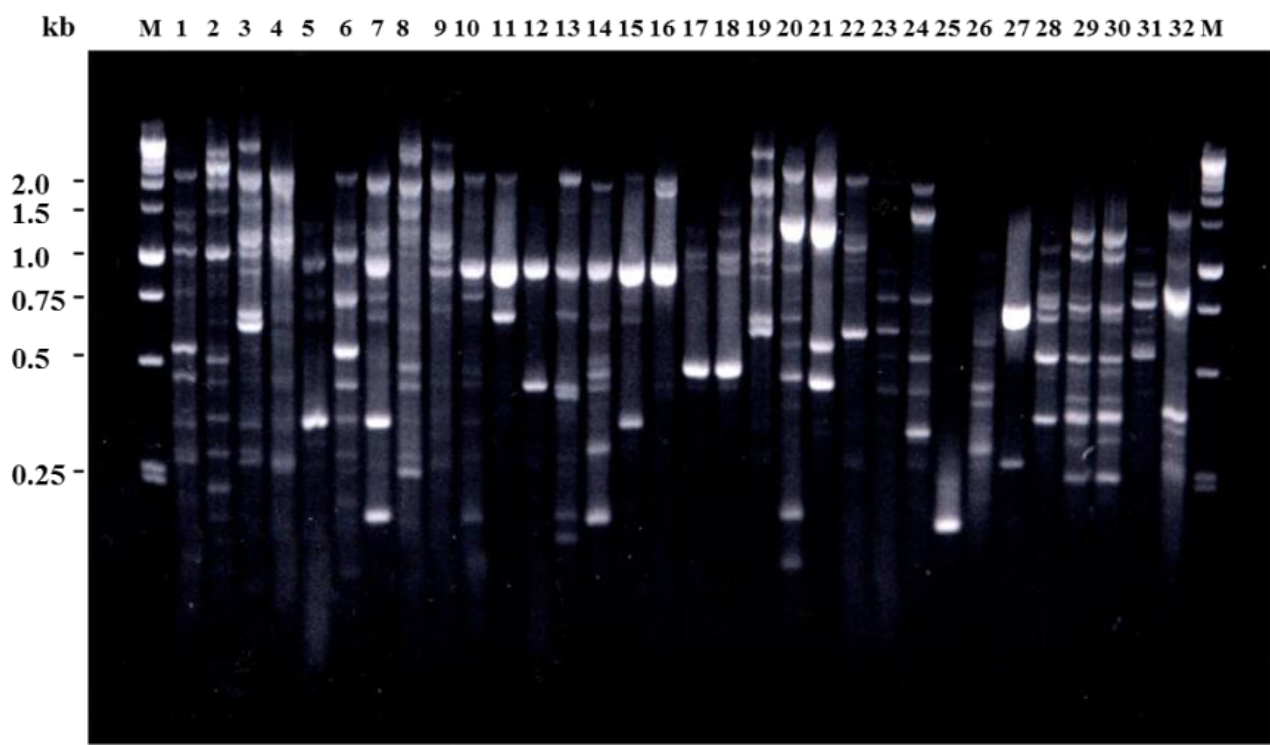

Fig. 1. PCR fingerprinting of different plant pathogenic bacterial strains by URP 4. M: 1kb DNA ladder (Promega), 1-24: Pectobacterium carotovoum subsp. carotovorum, 25: Xanthomonas axonopodis pv citri, 26: Pseudomonas sp. 27: Pseudomonas solanocearum, 28: Rhizobium leguminosarum, 29: Pseudomonase pv phaseoliala, 30: Pseudomonas marginalis, 31: Xanthomonas campestris pv. campestris, 32: Pseudomonas syrinage pv syringae

(A)
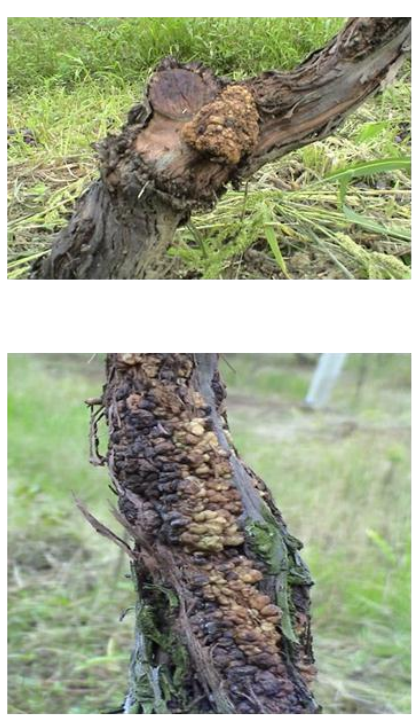

(B)

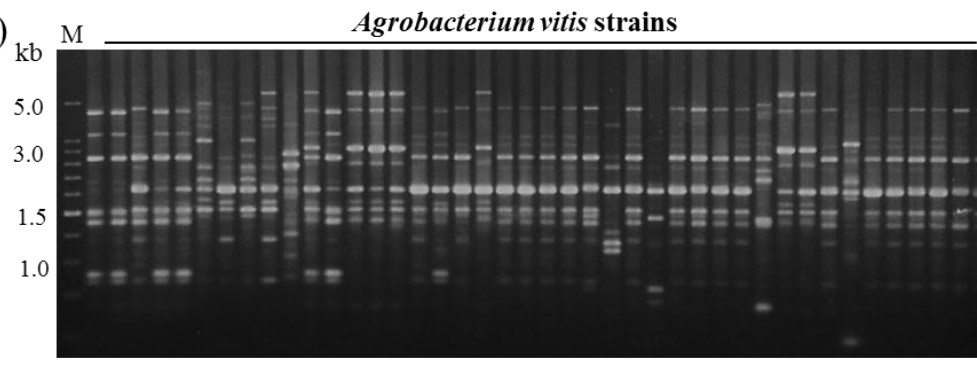

(C)

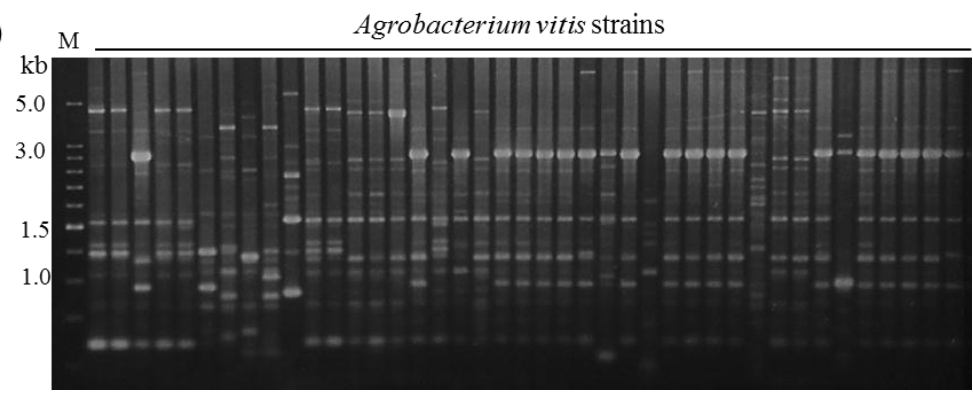

Fig. 2. URP-PCR polymorphism of Agrobacterium vitis strains, causal agent of crown gall on grapevine (A) detected by URP 2 (B) and URP 4 (C) 
PCR-based methods are cheaper, of $55^{\circ} \mathrm{C}$. REP-PCR and ERIC-PCR easier and provide faster results; these fingerprinting methods using repeated methods include Random Amplified sequence DNA of bacteria are limited in Polymorphic DNA PCR (RAPD-PCR), bacterial species retaining the sequence, Repetitive extragenic palindromic PCR whereas URP-PCR can universally apply in (REP-PCR) and Enterobacterial Repetitive genomes from diverse bacteria strains Intergenic Consensus PCR (ERIC-PCR). without the reasonable sequence information These methods have been successfully on bacteria in advance. In particular, species applied for typing many bacteria (Anita et al. or strain specific PCR fragment generated 2005; Johnson and Bryan, 2000; Williams et from URP-PCR products could be used in al. 1990). RAPD. Nevertheless, AP-PCR developing SCAR primers, which useful for have been pointed out as low reproducibility specifically detecting Agrobacterium vitis problems as they are applied with annealing and Pectobacterium carotovoum subsp. temperatures below $40^{\circ} \mathrm{C}$. On the other hand, carotovorum (Kang et al., 2003; Lim et al., the URP-PCR can achieve stable PCR results 2007). because it has a high annealing temperature 
Table 1. Oligonucleotide sequences of URP primers and their PCR applicability on bacterial strains

\begin{tabular}{llccc}
\hline Primers & Sequences (5'-3') & $\begin{array}{l}\text { GC } \\
\text { Conte }\end{array}$ & $\begin{array}{l}\text { Tm } \\
\left({ }^{\circ} \mathbf{C}\right)\end{array}$ & $\begin{array}{l}\text { Applicability } \\
\text { on bacterial strains }\end{array}$ \\
\hline URP1 & ATCCAAGGTCCGAGACAACC & 50 & 65 & Yes \\
URP2 & CCCAGCAACTGATCGCACAC & 50 & 65 & Yes \\
URP3 & AGGACTCGATAACAGGCTCC & 50 & 66 & Yes \\
URP4 & GGCAAGCTGGTGGGAGGTAC & 50 & 65 & Yes \\
URP5 & ATGTGTGCGATCAGTTGCTG & 50 & 67 & Yes \\
URP6 & TACATCGCAAGTGACACAGG & 50 & 68 & No \\
URP7 & AATGTGGGCAAGCTGGTGGT & 55 & 74 & Yes \\
URP8 & GATGTGTTCTTGGAGCCTGT & 50 & 65 & Yes \\
URP8 & GGACAAGAAGAGGATGTGGA & 50 & 65 & No \\
URP9 & TACACGTCTCGATCTACAGG & 50 & 65 & No \\
URP10 & AAGAGGCATTCTACCACCAC & 50 & 65 & \\
\hline
\end{tabular}

Genomic DNA of 225 strains in 45 bacterial species were used as templates for URP-PCR fingerprinting. The applicability of URP-PCR represents Yes, No and ND (Not determined)

In the following experiment, URP- $M$. scroflaceum strains that are the most PCR was applied to identification between or common cause of cervical lymphadenitis in within human and animal -related bacterial children, M. fortuitum is one of the many species. As representative bacterial materials, species of nontuberculosis mycobacteria genomic DNAs extracted from (NTM) that are commonly found in the Mycobacterium spp. including 4 environment. M. canettii, a novel pathogenic Mycobacterium intracellularae, strains, $4 \mathrm{M}$. taxon of the Mycobacterium tuberculosis avium strains, 3 M. scrofllaceum strains, M. complex (MTBC) (Hirsh et al., 2004), M. fortuitum, M. gallinarum, M. canetti, and M. smegmatis is commonly used in work on the smegmatis. M. intracellularae, M. avium and Mycobacterium genus due to its being a "fast 
grower" and non-pathogenic (Simner et al.,

2013).

(A)

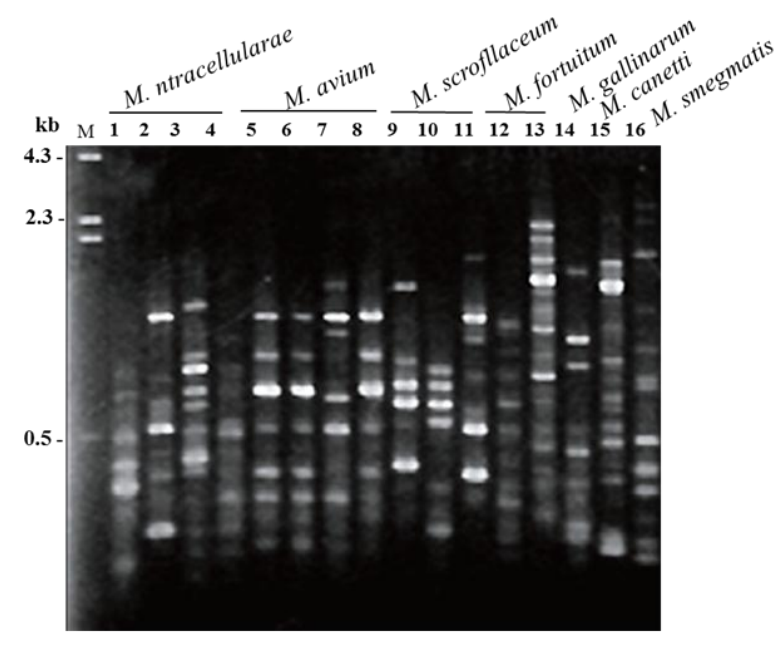

(B)

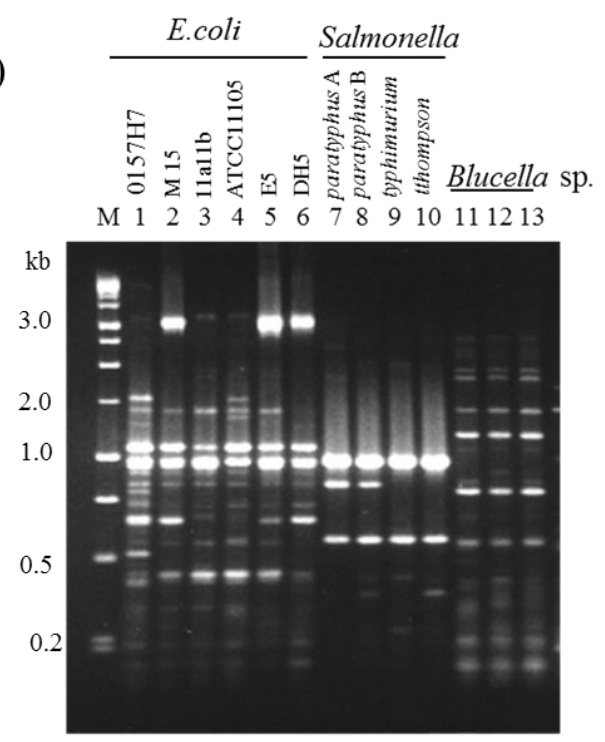

Fig. 3. PCR fingerprinting of human and animal related different bacterial species Mycobacterium spp. (A), Echerichia coli strains, Salmonella spp. and Blucella (B) by URP2R.

Mycobacterium avium-intracellulare infection (MAI) is an atypical mycobacterial infection, i.e. one with nontuberculous mycobacteria or NTM, caused by Mycobacterium avium complex ("MAC"), which is made of three mycobacteria species, M. avium, $M$. intracellulare, and $M$. chimaera (Horsburgh.et al., 1985) This infection causes respiratory illness in birds, pigs, and humans, especially in immunocompromised people. As shown in Fig.3 (A), PCR polymorphism dependent on the strains was observed on PCR amplicons of Mycobacterium spp., suggesting URPPCR is useful for strain typing within the bacterial species. In addition, several human animal pathogenic bacteria were tested for confirming usefulness of URP-PCR. Non pathogenic Escherichia coli including strains ATCC11105, 111a111b, M15 and pathogenic E. coli $\mathrm{O} 157: \mathrm{H} 7$ that is one of the Shiga toxin-producing type and is a cause of disease, typically foodborne illness of the "colonic escherichiosis" type ( Furrer et al., 1990). E. coli strains, Salmonella spp. and Blucella abortus strains were used as 
template DNA and were amplified by also examined. A polymorphic band of 0.8 primer URP-3(Fig. 3B). The E. coli kb was observed on only S. paratyphus A, O157:H7 specific PCR polymorphic bands and S. paratyphus B, showing its specific were observed on size marker of $0.5 \mathrm{~kb}$ and PCR fragment in the bacterial species. other polymorphic bands were showed in Nevertheless, URP-PCR polymorphism of reliance on E. coli strains. As a result, six E. Blucella abortus strains was identical in the coli strains were divided into four types. strains. Consequently, URP-PCR yielded Salmonella thompson, S. typhimurium, $S$. distinct PCR profiles that permitted paratyphus A, and S. paratyphus B that are differentiation among them at interspecies causal agents of Salmonellosis, food level, and furthermore, ubiquitous strain poisoning (McClelland et al., 2001; Bej et al., types were observed within E. coli strains 1994), and animal and human pathogenic and Salmonella species. bacteria species such as Brucella strains were

(A)

(B)

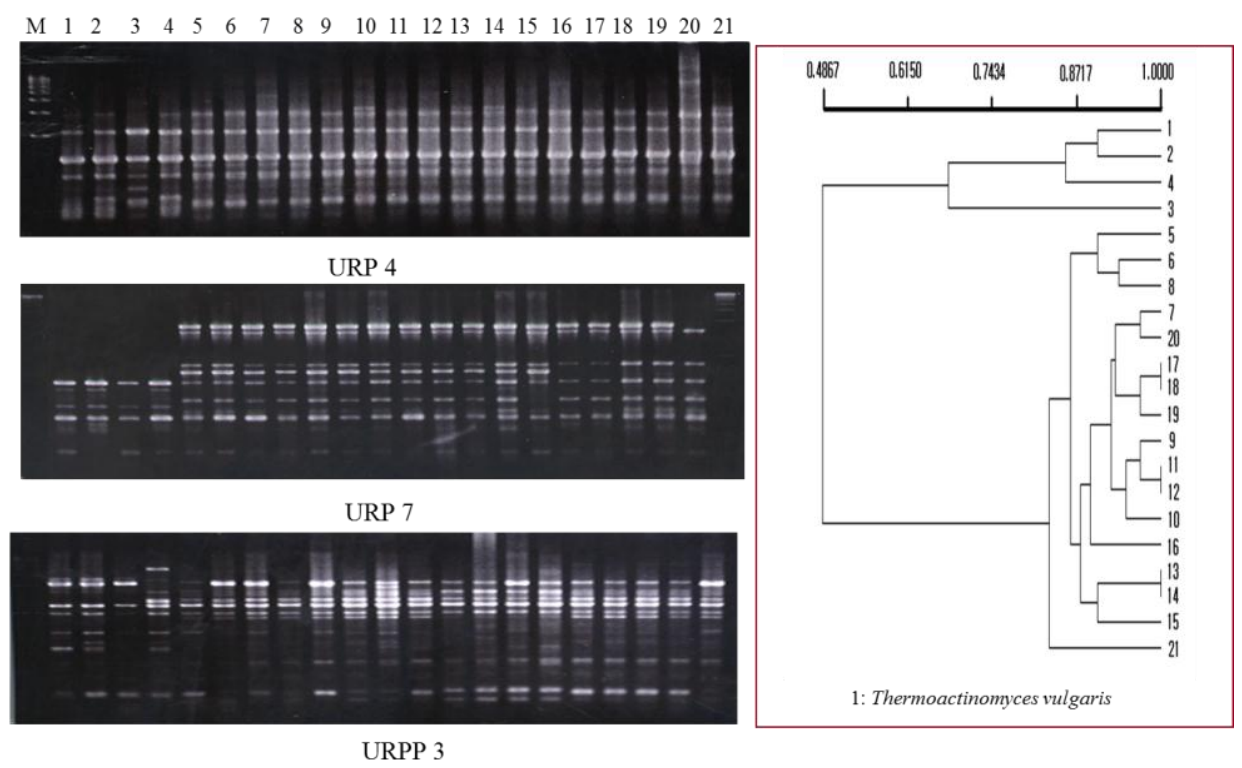

Fig. 4. URP-PCR profiles (A) and the PCR bands based UPGMA dendrogram (B)of hemophilic bacterial strains isolated from compost fermented with high temperature

Finally, thermophilic bacteria that was used for URP-PCR. Genomic DNAs were randomly isolated from high were amplified by primers URP 3, URP 4 temperature $\left(45-55^{\circ} \mathrm{C}\right)$ fermented compost and URP 7 (Fig. 4 A) and resultant 
polymorphic bands were scored to construct dendrogram. As showed in dendrogram data of Fig. 4 B, the bacteria were divided into two large groups containing culture collection, Thermoactinomyces vulgaris and further five subgroups were formed within the bacterial strains, showing different genetic relationships.

The data obtained from studies of various bacteria suggests that URP-PCR is potentially a valuable tool in the characterization and grouping at inter- and intraspecific levels of various bacterial species associated with medical, agricultural, industrial, and environmental fields. In many experiments using additional bacterial species, it was found URP-PCR allows generating discrete DNA fragments that are species or strain -specific. The speciesspecific URP-PCR products are easily excised from gels and cloned or re-amplified with the same primer to be used as a probe, providing an alternative strategy in developing specific Sequence-characterized amplified region (SCAR) markers that detect target microbial species or strain. Previously, such strategy was successfully used to develop specific DNA probe that detects Pectobacterium carotovorum subsp. carotovorum and A. vitis among other bacteria (Kang et al., 2003; Lim et al., 2006).

\section{CONCLUSIONS}

PCR approach using URP primers offers a powerful tool for studying DNA diversity of prokaryotic genomes, with potential use in taxonomic and phylogenic analysis, as well as in genotypic screening of strains in species, especially at inter- and intra-species levels. The URP-PCR is clearly different to RAPD (Williams et al., 1990) and AP-PCR method (Welsh et al., 1990) using arbitrary selected-primers because of long primer and high annealing temperature. It was believed that such URP-PCR conditions result in highly reproducible amplification products from organisms. This result suggested universal applicability of URPPCR to human, animal, plant and industry related bacteria strains. Because URP primers can be applied to a wide range of bacterial species, mass screen of bacterial resources and database construction of DNA profile can be very useful for various purposes such as identifying genetic characteristics of specific strains. However, it remains to elucidate how URP primers designed from 
repetitive sequence of rice are able to produce DNA polymorphism on diverse bacteria genomes with high specificity at inter- and intra-species. Nevertheless, it is reasonably assumed that complementary sequences to URP primers are widely dispersed in the diverse bacterial genomes that may play a critical evolutionary role.

\section{REFERENCES}

Ausubel, F. M. T., Brent, R., Kingston, R. E., Moore, D. D., Seidman, J. G., Smith, J. A., Steria ruhl, K. (1987). Current protocols in molecular biology. Greene Publishing Associates Wiley Interscience, New York.

Aggarwal, R., Singh, V., Shukla, R., Gurjar, M., \& Sharma, T. (2010). URP-based DNA fingerprinting of bipolaris sorokiniana isolates causing spot blotch of wheat. J. Phytopath, 158, 210-216.

Aggarwal, R., Tripathi, A., \& Yadav, A. (2010). Pathogenic and genetic variability in Tilletia indica monosporidial culture lines using universal rice primer-PCR Eur. J. Plant Pathol, 128, 333-342

Bej, A. K., Mahbubani, M. H., Boyce, M. J., \& Atlas, R. M. (1994). Detection of Salmonella spp. In oysters by PCR. Appl. Environ. Microbial, 60, 368-373.

Caetano-Anolles, G. 1994. MAAP: a versatile and universal tool for genome analysis. Plant Molecular Biology, 25, 1011-1026.

Caetano-Anolles, G., \& Gresshoff, P. M. (1997). DNA markers: protocols, Applications, and overviews. WILEYVCH, N.Y

Caetano-Anolles, G., Bassam, G. J., \& Gresshoff, P. M. (1992). Primertemplate interactions during DNA amplification fingerprinting with single arbitrary oligonucleotides. Mol. Gen. Genet, 235, 157- 165.

Chang, H. C., Wei, Y. F., Dijkshoorn, L., Vaneechoutte, M., Tang, C. T., et al. (2005). Species-level identification of isolates of the Acinetobacter calcoaceticus Acinetobacterbaumannii complex by sequence analysis of the 16S-23S rRNA gene spacer region. $J$ Clin Microbiol, 43, 1632-1639

Chang, H. R., Loo, L. H., Jeyaseelan, K., Earnest, L., \& Stackebrandt, E. (1997). Phylogenetic Relationships of Salmonella typhi and Salmonella typhimun'um Based on 16s rRNA Sequence Analysis. International Journal of Systematic Bacteriology, 47, 1253-1254.

De Brujin, F. J. (1992). Use of repetitive (repetitive extragenic pal-indromic and enterobacterial repetive intergenic consensus) sequences and the polymerase chain reaction to fingerprint the genomes of Rhizobium meliloti isolates and other soil bacteria. Appl. Environ. Microbiol, 58, 21802187.

Jaimes-Diaz, H., Garcia-Chequer, A. J., 
Mendez-Tenorio, A., SantiagoHemadez, J. C., Maldonado-Rodriguez, R., \& Beattie, L. L. (2011). Bacterial classification using genomic fingerprints obtained by virtual hybridization. J Microbiol Methods. 87, 286-94.

Furrer, B., Candrian, U., \& Luethy, J. (1990).

Detection and identification of Escherichia coli producing heat-labile enterotoxin type I by enzymatic amplification of a specific DNA fragment. Lett. Appl. Microbial. 10, 3134.

Garrity, G. M., Johnson, K. L., Bell, J. A., \& Searles, D. B. (2002). Taxonomic Outline of the Procaryotes. Bergey's Manual of Systematic Bacteriology, Second Edition, Release 3.0., SpringerVerlag, New York. 365 pages.

Hirsh, A. E., Tsolaki, A. G., DeRiemer, K., Feldman, M. W., \& Small, P. M. (2004). Stable association between strains of Mycobacterium tuberculosis and their human host populations. Proc Natl Acad Sci U S A, 101, 4871-4876.

Hong, S. K., Kim, W. K., Yun, H. G., \& Choi, K. J. (2008). Morphologicalvariations, genetic diversity and pathogenicity ofColletotrichum species causing grape ripe rot in Korea. Plant Pathol. J, 24, 269-278

Horsburgh, C. R, Mason, U. G., Farhi, D. C., \& Iseman, M. D. (1985). Disseminated infection with Mycobacterium aviumintracellulare. A report of 13 cases and a review of the literature. Medicine, 64,
$36-48$.

Hulton, C. J. S., Higgins, C. F., \& Sharp, P. M. (1991). ERIC sequences: a novel family of repetitive elements in the genomes of Escherichia coli, Salmonella typimurium and other enterobacteria. Molecular Microbiology, $5,825-834$.

Jana, T. K, Singh, N. K., Koundal, K. R., \& Sharma, T. R. (2005). Genetic differentiation of charcoal rot pathogen, Macrophomina phaseolina, into specific groups using URP-PCR. Canadian J. Microbiol, 51, 159-164.

Johnson, J. R., \& O'Bryan, T. T. (2000). Improved Repetitive-Element PCR fingerprinting for resolving pathogenic and nonpathogenic phylogenic groups within Escherichia coli. Clin Diagn Lab Immunol, 7:265-273

Kang, H. W. (2012). Genetic Divesity Analysis of Fungal Species by Universal Rice Primer (URP)-PCR. The Korean Journal of Mycology, 40, 78-85.

Kang, H. W., Kwon, S. W., \& Go, S. J. (2003). PCR-based specific and sensitive detection of Pectobacterium carotovorum ssp. carotovorum by primers generated from a URP-PCR fingerprinting-derived polymorphic band. Plant pathology, 52, 127-133.

Kang, H. W., Go, S. J., \& Eun, M. Y. (2002). Fingerprinting of diverse genomes using PCR with universal rice primers generated from repetitive sequence of Korean weedy rice. Molecular Cells, $13,1-7$. 
Kang, H. W., Park, D. S., Park, Y. J., You, C. H., Lee, B. M. and Go, S. J. (2001). Genomic differentiation among oyster mushroom cultivars released in Korea by URP-PCR fingerprinting. Mycobiology, 29, 85-89.

Kang, H. W., Park, D. S., Park, Y. J., Lee, B. M., Cho, S. M., Kim, K. T., Seo, K. S., \& Go, S. J. (2002). PCR based detection of Phellinus linteus using specific primers generated from universal rice primer (URP) derived PCR polymorphic band. Mycobiology, 30, 202-207.

Kang, H. W. \&Kang, K. K. (2008). Genomic characterization of Oryza speciesspecific CACTA-like transposon element and its application for genomic fingerprinting of rice varieties. Molecular Breeding, 21, 271-281.

Lim, S. H., Kim, J. K., \& Kang, H. W. (2007). Novel SCARprimers forspecific and sensitive detection of Agrobacterium vitis strains. Microbiological Research, 164, 451-460.

McClelland, M., Sanderson, K. E., Spieth, J., Clifton, S. W., \& Latreille, P. (2001). Complete genome sequence of Salmonella enterica serovar Typhimurium LT2. Nature, 413, 852856.

Simner, P. J., Buckwalter, S. P., Uhl, J. R., \& Wengenack, N. L. (2013). Identification of Mycobacterium Species and Mycobacterium tuberculosis Complex Resistance Determinants by Use of PCRElectrospray Ionization Mass
Spectrometry. J Clin Microbiol, 51, 3492-3498.

Welsh, J., Petersen, C., \& McClelland, C. (1990). Polymorphisms generated by arbitrarily primed PCR in the mouse: application to strain identification and genetic mapping. Nucleic Acids Res, 19: 303-306.

Williams, J. G. K., Kubelic, A. R., Livak, K. J., Rafalski, J. A., \& Tingey, S. V. (1990) DNA polymorphisms amplified by arbitray primers are useful as genetic markers. Nucleic Acid Res, 18, 6531-6535. 